\section{Temperature rise in cavities prepared by high and low torque handpieces and Er:YAG laser}

\author{
L. Firoozmand, ${ }^{1}$ R. Faria, ${ }^{2}$ M. A. Araujo, ${ }^{3}$ R. di Nicoló ${ }^{4}$ and M. F. Huthala ${ }^{5}$
}

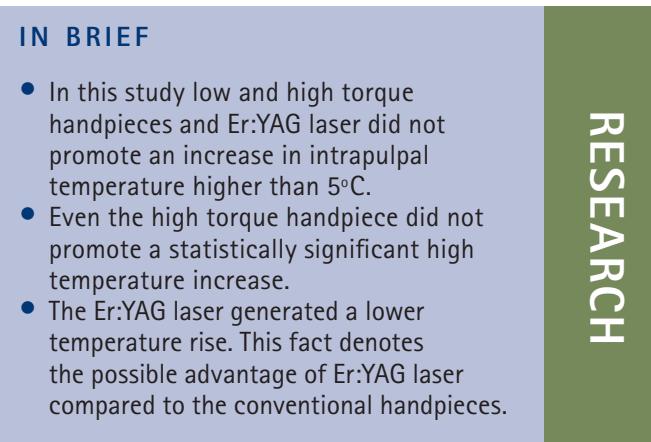

Objective The aim of this study was to compare intrapulpal temperature increases produced by a high-speed high-torque (speed-increasing) handpiece, a high-speed low-torque handpiece (air-turbine) and an Er:YAG (Erbium: Yttrium-Aluminum-Garnet) laser. Subject and methods Thirty bovine incisors were reduced to a dentine thickness of $2.0 \mathrm{~mm}$. Class V preparations were prepared to a depth of $1.5 \mathrm{~mm}$, measured with a caliper or by a mark on the burs. A thermocouple was placed inside the pulp chamber to determine temperature increases $\left({ }^{\circ} \mathrm{C}\right)$. Analysis was performed on the following groups $(n=10)$ treated with: $G 1$, low-torque handpiece; $G 2$, high-torque handpiece; and G3, Er:YAG laser $(2.94 \mu \mathrm{m}$ at $250 \mathrm{~mJ} / 4 \mathrm{~Hz})$, all with water cooling. The temperature increases were recorded with a computer linked to the thermocouples. Results The data were submitted to ANOVA and Tukey statistical test. The average temperature rises were: $1.92 \pm 0.80^{\circ} \mathrm{C}$ for $\mathrm{G} 1,1.34 \pm 0.86^{\circ} \mathrm{C}$ for $\mathrm{G} 2$, and $0.75 \pm 0.39^{\circ} \mathrm{C}$ for $\mathrm{G} 3$. There were significant statistical differences among the groups $(p=0.095)$. All the groups tested did not have a change of temperature that exceeds the threshold of $5.5^{\circ} \mathrm{C}$. Conclusion Temperature response to the low and high torque handpieces seemed to be similar, however the Er:YAG laser generated a lower temperature rise.

\section{INTRODUCTION}

It is usually necessary to remove caries and provide an adequate shape to receive the restorative material prior to applying dental materials on dental structures. The tooth preparation can be done with a conventional (high-speed low-torque air turbine) or modified (high-speed hightorque) handpiece.

The use of lasers in dentistry is an alternative method that is gaining importance, as the laser can provide more comfort to the patient by reducing pain, noise and need for an anaesthetic. ${ }^{1}$

Dentine is a structure full of tubules. At deep dentine, less dentine is observed between the tubules, while the tubules

\footnotetext{
${ }^{1^{*}-5}$ Faculty of Dentistry UNESP, Restorative Dentistry, Av. Eng. Francisco José Longo, 777 - Jd São Dimas, São José dos Campos 12245-000 SP, Brazil

${ }^{*}$ Correspondence to: Dr Leily Firoozmand Email: leilyfiroozmand@hotmail.com
}

\section{Online article number E1}

Refereed Paper - accepted 14 November 2007

DOI: $10.1038 /$ sj.bdj.2008.491

${ }^{\circledR}$ British Dental Journal 2008; 205: E1 present a greater diameter, promoting greater conduction of thermal stimuli. The movement of dentinal fluid and the hydraulic ability to generate pressures on the pulpal tissue occurs through the dentine tubules. ${ }^{2}$ Analysis of the hydrodynamic stimulus inside the tubules reveals that the rapid movement of dentinal fluid induces pain. ${ }^{3}$ The hydraulic pressure decreases with increasing distance from the pulp and dentine thickness. ${ }^{4}$

Temperature increase is able to promote alterations in pulpal tissue. Zach \&t Cohen ${ }^{5}$ performed an in vivo study that demonstrated that 15\% of monkey teeth in their study that had an intrapulpal temperature rise of $5.5^{\circ} \mathrm{C}$ were irreversibly damaged. The main cause of postoperative inflammation or necrosis of the pulp is probably due to the injury of dentine, a tissue in direct functional and physiological connection with the pulp. ${ }^{6}$

High-speed handpieces are perhaps the most important equipment in a dental office. ${ }^{7}$ Differences in cutting mechanisms were seen between handpieces with high and low torque, especially when the loads and cutting rates were increased. ${ }^{8}$ The high-speed handpieces generated an increase in pulpal temperature and pressure that decreased with an increase in the thickness of the remaining dentine. ${ }^{9}$

Because the wavelength of the Er:YAG (Erbium:Yttrium-Aluminum-Garnet) laser can absolve water and hydroxyapatite, ${ }^{10}$ it can be indicated for the removal of caries and cavity preparations. ${ }^{11,12}$ Some Er:YAG laser beams can penetrate to deeper areas than the ablated area; damage of the nerve fibres and terminals might be a mechanism of pain reduction in cavity ablation with Er:YAG laser. ${ }^{1}$

The treatment with an Er:YAG laser needs to be performed with constant water cooling because macroscopic observations of the dentine irradiated without water cooling showed dark lesions, suggesting carbonisation of the tissue. ${ }^{13}$ Under constant water cooling, the high-speed turbine and laser instrument generate similar heat increases; water cooling is essential to avoid destructive temperature increases. ${ }^{14}$ 
The purpose of this study was to compare the intrapulpal temperature changes when the teeth were treated with high-speed handpieces (low and high torque) and an Er:YAG laser. The null hypotheses of this study are that high torque handpiece causes a rise in the intrapulpal temperature and that the Er:YAG laser induces a smaller intrapulpal temperature change.

\section{MATERIALS AND METHODS}

In this study, 30 freshly extracted intact erupted bovine incisors were used. The specimens were stored in distilled water and frozen at $-18^{\circ} \mathrm{C}$ until they were used..$^{15}$ This study was approved by the Ethical Committee of School of Dentistry - UNESP, n.015/2006-PA/CEP.

The roots were sectioned at the third cervical with a carborundum disc and disposed. The coronal pulp was removed with a dentineal curet (Duflex Lucas \# 86, SSWhite, Rio de Janeiro, RJ, Brazil) and endodontic $\mathrm{H}$ files (H 20, 25, 30, Maillefer), and the pulp chamber was irrigated with distilled water and gently dried with air.

The buccal surfaces were ground under water cooling with $\mathrm{SiC}$ grit 80 paper, mounted on a trimming machine (Kohl Bach, Motores Elétricos, Jaraguá do Sul, SC, Brazil), to remove the enamel and expose the dentine. During this procedure, a caliper was used to standardise the dentine thickness at $2 \mathrm{~mm}$.

Subsequently, the mesial and distal faces of the specimens were reduced in the trimming machine, to allow the fixation of the specimens in a container with water and a thermostat, to maintain the temperature at $36 \pm 1^{\circ} \mathrm{C}$. All the specimens were also sectioned in the incisal and cervical face, the size of the specimens were standardised to $10 \mathrm{~mm}$, and half of this distance ( $5 \mathrm{~mm}$ ) was demarcated as the preparation area.

The teeth were divided into three groups, with ten specimens each, for each piece of equipment used to prepare the cavity (Table 1).

\section{Cavity preparation}

The cavity preparations of G1 and G2 were made under constant water cooling with spherical diamond burs (1015; KG Sorensen, Barueri, São Paulo, Brazil).

\begin{tabular}{|c|c|c|c|}
\hline Group & Equipment & Manufacturer & Specifications \\
\hline G1 & $\begin{array}{l}\text { Air turbine } \\
\text { Low torque Handpiece }\end{array}$ & Kavo & Extratorque 605 \\
\hline G2 & High torque Handpiece & WEtH & Speed increasing $(1: 5)$ \\
\hline G3 & Er:YAG Laser & Key III (Kavo, Germany) & $\begin{array}{l}250 \mathrm{~mJ}, 4 \mathrm{~Hz}, 80,19 \mathrm{~J} / \mathrm{cm}^{2} \\
\text { density energy. }{ }^{*}\end{array}$ \\
\hline
\end{tabular}

A new bur was used for every five teeth preparations to maintain a constant cut and consequently, a constant pressure and heat in the teeth. For each cavity preparation, the diamond spherical bur (with a stop in $1.5 \mathrm{~mm}$ ) was inserted in the dentine until there was a remaining dentine thickness of $0.5 \mathrm{~mm}$. A low-load preparation technique was used, with two seconds of cutting alternated with one second of rest and a 50 to $80 \mathrm{~g}$ load applied on the turbine. The load was measured by preparing the teeth on a laboratory scale (AS 5000 Marte Equipamentos de Medição, São Paulo, Brasil) (Fig. 1).

For G3, the Er:YAG laser Key III (Kavo, Alemanha) was used with a wavelength of $2.94 \mu \mathrm{m}$, and special tip for cavity preparation $n^{0} 2060$, using the "no contact' mode, with constant water cooling. During this procedure, a caliper was used to check the remaining dentine thickness of $0.5 \mathrm{~mm}$. The bovine dentine was protected with Teflon tape used to demarcate the area to be irradiated with the laser.

\section{Recording of temperature changes}

All specimens had a thermal-conductive paste inserted into the pulp chamber to facilitate the heat conduction from the chamber walls to the thermocouple. The active apex of $\mathrm{T}$ thermocouple (copper $(+) \mathrm{x}$ constantan $(-))$ was inserted in a way so that was in direct contact with the internal buccal dentine wall, next to the place where the tooth was prepared. The pulp chamber was filled out and the apical portion of the tooth was sealed with an adhesive mass (Multi-Tak/Pritt) to firmly hold the thermocouple in the correct position. The thermocouple was positioned at a height of $5 \mathrm{~mm}$, corresponding to the standardised measure presented previously. The temperature rises were recorded with a data collector

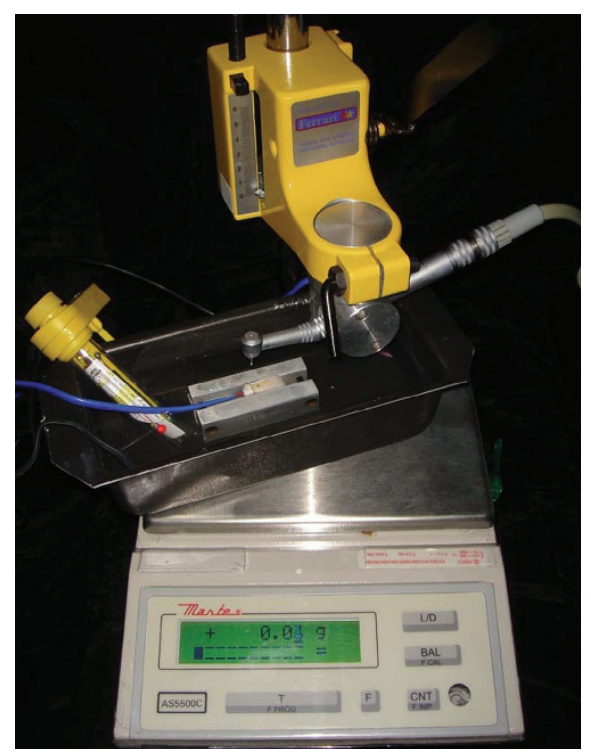

Fig. 1 Tooth in position on the laboratory scale before starting the cavity preparation

(ADS 2000 IP-Lynx, Tec. Eletr., Brazil) linked to a personal computer. The initial and peak temperatures were recorded during the cavity preparations.

Data were organised and analysed using the one-way analysis of variance (ANOVA) and Tukey statistical test.

\section{RESULTS}

The pulpal temperature changes during tooth preparation in deep cavities (0.5 $\mathrm{mm}$ remaining dentine thickness) are presented in Table 2.

The temperature values obtained are represented though columns of dispersion (points graph, dot plot and box-plot) and lines (mean and standard deviation) presented in Figure 2.

With the information presented in Table 2 and Figure 2, it is observed that the values do not present the same distribution around the mean. The dispersion index evaluated on the three groups by the statistical analyses (standard deviation) is not the same. The standard 
deviation of handpieces (low and high torque) present correspondent values, more than two times that of the Er:YAG laser standard deviation.

When comparing the central, mean and median tendencies of the data using the parametric statistical test, Analysis of Variance (ANOVA), Table 3, and nonparametric Kruskal-Wallis test $(\mathrm{kW}=$ 8.605; $\mathrm{df}=2 ; \mathrm{p}$-value $=0.0135<0.05$ ), it is observed that the groups are significantly different.

While comparing the mean values (Tukey's test) and median values (Dun's test), it is possible to verify that the low torque handpiece is different from the Er:YAG laser, while the high torque handpiece presents an intermediary behaviour between the values of the low torque handpiece and Er:YAG laser.

\section{DISCUSSION}

Several methods can be used to remove carious tissue and prepare the dental cavity. The purpose of this study was to compare the pulpal heat generated when teeth were prepared with an Er: YAG laser and a diamond bur on either a high-speed low-torque (air-turbine) or a high-speed high-torque (speedincreasing) handpiece.

In this study, cavity preparations were made on all specimens to a dentine thickness of $0.5 \mathrm{~mm}$, as it has been shown that, at this distance from the pulp, the injuries on dentine have a high effect on the pulpal tissue. ${ }^{3,4}$ The temperature variation using these handpieces was analysed to correlate the influence of this temperature alteration on the dental pulp. Srimaneepong et al. (2002), ${ }^{9}$ evaluated the temperature changes after the application of a Nd:YAG laser and a high-speed diamond bur with a remaining dentine thickness of 2.1, 1.5, 1.0 and $0.5 \mathrm{~mm}$. The results demonstrated that $0.5 \mathrm{~mm}$ dentine thickness had the highest increase of pressure and temperature in the pulp chamber.

For all of the studied groups in the current study, constant water cooling was used, because in agreement with Attrill et al. (2004), ${ }^{16}$ the absence of water cooling can promote great increases in temperature.

While analysing the behaviour of low and high torque handpieces, Watson et

\section{Table 2 Temperature increases $\left({ }^{\circ} \mathrm{C}\right)$ for test groups}

\begin{tabular}{|l|l|l|l|} 
& high-speed low-torque & high-speed high-torque & Er:YAG laser \\
\hline Mean $\left({ }^{\circ} \mathrm{C}\right)$ & 1.77 & 1.40 & 0.74 \\
\hline Median $(\mathrm{SD})$ & $1.92(0.80)$ & $1.34(0.86)$ & $0.75(0.39)$ \\
\hline Maximum value & 3.0 & 3.4 & 1.6 \\
\hline Minimum value & 0.24 & 0.51 & 0.25 \\
\hline$*(n=10)$ & & \\
\hline
\end{tabular}

Table 3 ANOVA (1 way) for all records of temperature change

\begin{tabular}{l|l|l|l|l|l}
\hline Source & DF & SS & SM & F & p \\
\hline Equipment & 2 & 5.4689 & 2.73446 & 5.31 & $0.0114^{*}$ \\
\hline Residue & 27 & 13.9081 & 0.51512 & & \\
\hline Total & 29 & 19.3771 & & & \\
\hline$*(n=10)$ & & & & & \\
\hline
\end{tabular}

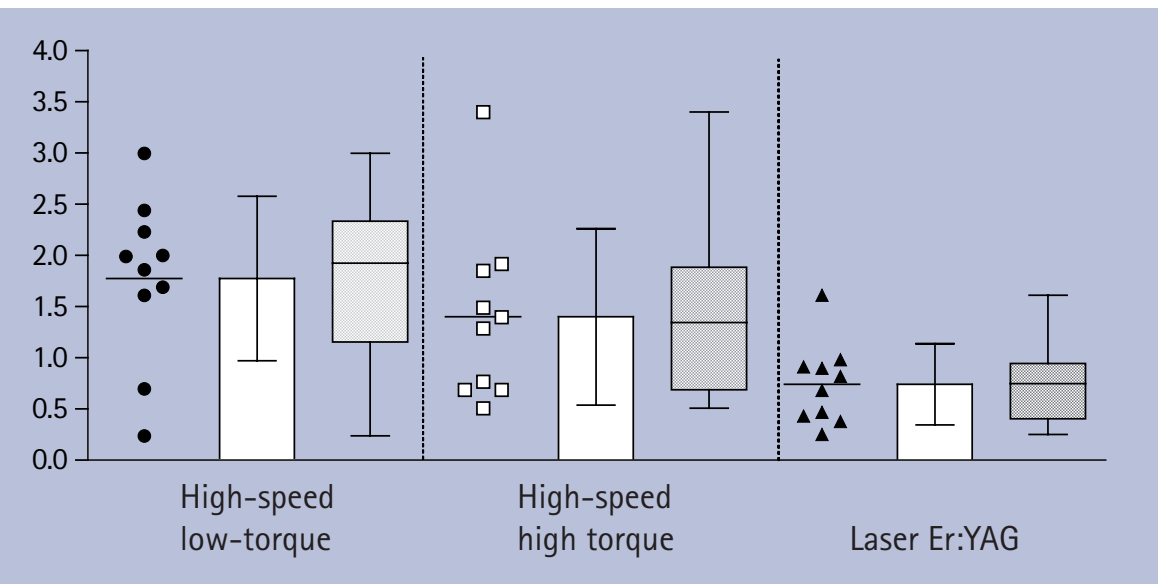

Fig. 2 Dot plot graph (around the mean), box-plot and bars columns for all the values of temperature alterations $\left({ }^{\circ} \mathrm{C}\right.$ ) obtained during cavity preparation

al. $(2000)^{8}$ verified that there was no evidence of increased tooth cracking or heating with these handpieces, indicating no deleterious effects on the tooth. The results obtained in the current study allowed us to verify that using low and high torque handpieces did not present significant statistical differences.

The Er:YAG was also used in this study to prepare the cavity on deep dentine, because, according to Hibst and Keller (1989), ${ }^{17}$ the Er:YAG laser offered high ablation efficiency and low thermal side effects. Some Er:YAG laser beams could penetrate to deeper areas than the ablated area and damage the nerve fibres and terminals, which might be a mechanism of pain reduction in cavity ablation with the Er:YAG laser. ${ }^{1}$
A number of authors ${ }^{10,13,16,18-23}$ studied the behaviour of different lasers to determine the amount of temperature increase during cavity preparation on dental structure.

Keller et al. (2003) ${ }^{19}$ verified a mean temperature rise of $1.68^{\circ} \mathrm{C}$ in the pulpal chamber using $\mathrm{CO}_{2}$ and morphologically unaltered dentine surfaces, demonstrating the safe and tissue preserving character of the laser. But Malmstrom et al. (2001) ${ }^{21}$ using pulsed $\mathrm{CO}_{2}$ laser light for soft tissue surgery found detrimental changes to oral hard tissue and to the pulp. The pulp chamber temperature rise ranged from 0.5 to $19^{\circ} \mathrm{C}$ degrees depending on the distance of pulp chamber, also SEM revealed crystal fusion in both enamel and dentine tissue. Others 
$\mathrm{CO}_{2}$ laser effects on tooth morphology, pulp tissue and pulpal blood flow were observed by Watanabe et al. (1996) $)^{22}$ and Friedman et al. (1992). ${ }^{23}$

Srimaneepong et al. (2002) ${ }^{9}$ verified that, during the use of a Nd:YAG laser, there was an increase in pulpal temperature and pressure as the power (and corresponding energy density) of laser irradiation increased and the remaining dentine thickness decreased. The $3 \mathrm{~W}$ laser (energy density $467 \mathrm{~J} \mathrm{~cm}^{-2}$ ) created the highest mean increase of pulpal temperature $\left(1.31^{\circ} \mathrm{C}\right)$ and pressure $(1.75$ $\mathrm{kPa}$ ), while the $1 \mathrm{~W}$ laser (energy density $156 \mathrm{~J} \mathrm{~cm}^{-2}$ ) promoted $0.34^{\circ} \mathrm{C}$ and $0.53 \mathrm{kPa}$ mean increase of temperature and pressure, respectively.

In the current study, the irradiation of the Er:YAG laser at energy density of $80.19 \mathrm{~J} / \mathrm{cm}^{2}$ created a mean increase in temperature of $0.74^{\circ} \mathrm{C}$. The reduced increase of temperature is in agreement with the findings of Keller \& Hibst $(1989){ }^{10}$ who verified that the majority of the incident energy is consumed in the ablative process and only a small fraction of the energy results in heating the remaining tissue, causing no damage. The reduction of temperature change is also obtained from the use of constant water cooling, in accordance with Attrill et al. (2004), ${ }^{16}$ who observed that the application of an Er:YAG laser without water cooling would exceed the temperature increase threshold of $5.6^{\circ} \mathrm{C}$.

Class I and class V cavity preparations with Er:YAG laser in enamel, cementum and carious tissue was carried out by Oelgiesser et al. (2003), ${ }^{18}$ at different irradiation energies (600-1000 mJ) and pulse frequencies (7-12 PPS), with an air-water spray as a cooling system. The authors stated that the elevation measured in the pulp chamber during lasing with various energies and pulse rates was low and did not exceed the critical value of $5.5^{\circ} \mathrm{C} .{ }^{5}$

There are few reports ${ }^{14,20,24}$ comparing the intrapulpal temperature rise during tooth preparation with Er: YAG laser and conventional burs with conflicting findings.

Thus, in relation to the use of Er:YAG laser or diamond burs for preparation of dental hard tissue, the results of the current study are in agreement with the Glockner et al. (1998) ${ }^{20}$ and Keller et al. $(2003)^{19}$ findings, observing a lesser increase in intrapulpal temperature during laser preparation in comparison to a conventional bur. The reduces increase in intrapulpal temperature might explain the reduction in pain with the clinical use of the Er:YAG laser. However, Armengol et al. (2000) ${ }^{24}$ and Cavalcanti et al. $(2003)^{14}$ stated that both the high-speed and laser instruments generated similar heat increases under water cooling.

The highest value of temperature alteration during tooth preparation, regardless of the equipment used was lower than the critical value of $5.5^{\circ} \mathrm{C},{ }^{5}$ in agreement with results found in the literature. ${ }^{18,24}$

Additionally, Chang \& Wilder-Smith $(1998)^{25}$ demonstrated that the laserinduced temperature increases were significantly greater in empty pulp chambers than in pulp-filled chambers. The presence of pulpal tissue, circulating blood and a high quantity of water in the dental structures, promotes heat dissipation that can lead to the deduction that the values found in this in vitro study would be less if evaluated in vivo.

\section{CONCLUSION}

Within the limits of this study, the null hypothesis that there would be a difference between the rise of intrapulpal temperature when cutting with high and low torque handpieces was rejected, as these groups did not present statistical differences. However, the null hypothesis that the Er:YAG laser would induce a smaller intrapulpal temperature change was accepted, as this laser promoted a smaller increase in intrapulpal temperature in comparison to the handpieces. All of the equipment used during cavity preparation, under water cooling, did not exceed the critical temperature of $5.5^{\circ} \mathrm{C}$.

1. Inoue H, Izumi T, Ishikawa H, Watanabe K. Shortterm histomorphological effects of Er:YAG laser irradiation to rat coronal dentine-pulp complex. Oral Surg Oral Med Oral Pathol Oral Radiol Endod 2004; 97: 246-250.

2. Ciucchi B, Bouillaguet S, Holz J, Pashley D. Dentineal fluid dynamics in human teeth, in vivo. J Endod 1995; 21: 191-194.

3. Pashley D H. Clinical correlations of dentine structure and function. J Prosthet Dent 1991;
66: 777-781.

4. Fogel H M, Marshall F J, Pashley D H. Effects of distance from the pulp and thickness on the hydraulic conductance of human radicular dentine. J Dent Res 1988; 67: 1381-1385.

5. Zach L, Cohen G. Pulp response to externally applied heat. Oral Surg Oral Med Oral Pathol 1965; 19: 515-530.

6. Baldissara P, Catapano S, Scotti R. Clinical and histological evaluation of thermal injury thresholds in human teeth: a preliminary study. J Oral Rehabil 1997; 24: 791-801.

7. Christensen $\mathrm{GJ}$ J. The high-speed handpiece dilemma. J Am Dent Assoc 1999; 130: 1494-1496.

8. Watson T F, Flanagan D, Stone D G. High and low torque handpieces: cutting dynamics, enamel cracking and tooth temperature. Br Dent J 2000 188: 680-686.

9. Srimaneepong V, Palamara J E, Wilson P R. Pulpal space pressure and temperature changes from $\mathrm{Nd}$ : YAG laser irradiation of dentine. J Dent 2002; 30: 291-296.

10. Keller U, Hibst R. Experimental studies of the application of the Er:YAG laser on dental hard sub stances. II. Light microscopic and SEM investigations. Lasers Surg Med 1989; 9: 345-351.

11. Visuri S R, Gilbert J L, Wright D D, Wigdor H A Walsh J T Jr. Shear strength of composite bonded to Er:YAG laser-prepared dentine. J Dent Res 1996; 75: 599-605.

12. Cozean C, Arcoria C J, Pelagalli J, Powell G L. Dentistry for the 21st century? Erbium:YAG laser for teeth. J Am Dent Assoc 1997; 128: 1080-1087.

13. Geraldo-Martins VR, Tanji E Y, Wetter N U, Nogueira R D, Eduardo C P. Intrapulpal temperature during preparation with the Er:YAG laser: an in vitro study. Photomed Laser Surg 2005; 23: 182-186.

14. Cavalcanti B N, Lage-Marques J L, Rode S M. Pulpal temperature increases with Er:YAG laser and high-speed handpieces. J Prosthet Dent 2003; 90: 447-451.

15. Camps J et al. Influence of tooth cryopreservation and storage time on microleakage. Dent Mater 1996; 12: 121-126.

16. Attrill D C, Davies R M, King T A, Dickinson M R, Blinkhorn A S. Thermal effects of the Er:YAG laser on a simulated dental pulp: a quantitative evaluation of the effects of a water spray. J Dent 2004; 32: $35-40$.

17. Hibst R, Keller U. Experimental studies of the application of the Er:YAG laser on dental hard substances. I Measurement of the ablation rate. Lasers Surg Med 1989; 9: 338-344.

18. Oelgiesser D, Blasbalg J, Ben-Amar A. Cavity preparation by Er-YAG laser on pulpal temperature rise. Am J Dent 2003; 16: 96-98.

19. Keller $O$ R, Weber FE, Gratz K W, Baltensperger M M Eyrich $\mathrm{G}$ K. Laser-induced temperature changes in dentinee. J Clin Laser Med Surg 2003; 21: 375-381.

20. Glockner K, Rumpler J, Ebeleseder K, Stadtler P. Intrapulpal temperature during preparation with the Er:YAG laser compared to the conventional burr: an in vitro study. J Clin Laser Med Surg 1998: 16: 153-157.

21. Malmstrom H S, McCormack S M, Fried D, Featherstone J D. Effect of $\mathrm{CO}_{2}$ laser on pulpal temperature and surface morphology: an in vitro study. J Dent 2001: 29: 521-529.

22. Watanabe I, Lopes R A, Brugnera A, Katayama A Y Gardini A E. Effect of $\mathrm{CO}_{2}$ laser on Class $V$ cavities of human molar teeth under a scanning electron microscope. Braz Dent J 1996; 7: 27-31.

23. Friedman S, Liu M, Izawa T, Moynihan M, Dorscher-Kim J, Kim S. Effects of CO laser irradiation on pulpal blood flow. Proc Finn Dent Soc 1992; 88 Suppl 1: 167-171.

24. Armengol V, Jean A, Marion D. Temperature rise during Er:YAG and Nd:YAP laser ablation of dentine. J Endod 2000; 26: 138-141.

25. Chang J C, Wilder-Smith P. Laser-induced thermal events in empty and pulp-filled dental pulp chambers. Lasers Surg Med 1998; 22: 46-50. 